\title{
Non-Specific ST-T Changes by ECG Finding
}

National Cancer Institute

\section{Source}

National Cancer Institute. Non-Specific ST-T Changes by ECG Finding. NCI Thesaurus.

Code C71031.

An electrocardiographic finding of changes in the ST segment and T wave that do not meet criteria for ischemia or infarction. 